\title{
AUGUSTE RODIN, EL CARÁCTER ESPECÍFICO \\ DE SU PROCESO CONFIGURATIVO
}

\author{
Manuel Núñez Rodríguez \\ Universidade de Santiago de Compostela
}

\begin{abstract}
RESUMEN
En este estudio se trata de analizar los diferentes factores que influyeron en la obra de Rodin, así como sus principales innovaciones como escultor, tanto en el tratamiento de las obras como en los diferentes factores que predominaron en el artista francés, con el que creó una obra rica en matices plásticos e innovadora en el mundo de finales del siglo XIX.
\end{abstract}

Palabras clave: Rodin, mano in pronazione, ritual de harmiscara, comportamiento kinésico, sinestesia

\begin{abstract}
This study sets out to analyse the various factors that influenced the work of Rodin and his main innovations as a sculptor, both in the treatment of his work and his influences, which he drew on to create art that was both rich in visual nuance and groundbreaking for the late nineteenth century.
\end{abstract}

Keywords: Rodin, mano in pronazione, harmiscara rite, kinesic behaviour, synaesthesia

Para formular el orden de ideas y de sentimientos que confirman las experiencias plásticas de Auguste Rodin (1840-1917), se dispone de las conversaciones mantenidas y posteriormente publicadas con Paul Gsell, Étienne DujardinBeaumetz, Camille Mauclair, su secretario Rainer María Rilke...; nombres a los que hay que añadir el no mencionado Émile-Verhaeren, poeta belga y crítico de arte, amigo de Rilke, Bertold Brech, Paul Valery, Rimbaud. Junto con estos autores, que tanto contribuuyeron a explorar diferentes aspectos de su vida y obra, también interesa destacar la realidad de aquella situación intelectual y política, como fue la desplegada en la Tercera República (1880-1920), momento en el cual Rodin y los pintores impresionistas conformaron la primera generación de artistas con entidad propia bajo este modelo político.

Los nuevos postulados teóricos de esta democracia liberal, habrían de abordar principios que constituyeron el fundamento de la misma; así, la puesta en vigor de cuanto cooperase a concordar el progreso de los derechos sociales en combinación con una serie de leyes que alentaran las libertades del ciudadano y de las partes necesarias que toda independencia exige para conformar un todo en el que participase por igual el sentido de la intencionalidad y de la responsabilidad. Por otro lado, consagrada la soberanía nacional sobre los valores originarios de la filosofía del Siglo de las Luces y de la Revolución Francesa, existe una controversia sin resolver, y que considera que a ésta no hay que juzgarla, pero sí comprenderla. Sin embargo, cuando Maurice Agulhon analizaba "quiénes eran dignos de un reconocimiento nacional en la III República"1, no dudaba en pronunciarse por la puntual correspondencia de la Revolución con un logro que también estaba impregnado de la filosofía del Siglo de las Luces, de todo un ideal de Razón, de fe entendida como progreso, de civismo, de filantropía y, por lo mismo, no resultaba desconcertante la valía de quienes eran merecedores de honores públicos confor- 
me a los aspectos emanados de su propia biografía; valoración a resaltar, por ejemplo, en Víctor Hugo, inhumado con descomunal cortejo en el Panteón el 1 de junio de 1885, con la circunstancia particular de encargos escultóricos a Rodin sembrados de desacuerdos por cuestiones de ajuste ${ }^{2}$. Ahora bien, la indiscutible valoración totalitaria es que su Víctor Hugo es Historia, y, en consecuencia, pasaría a ser, como diría Voltaire, prueba tangible de la "inmortalidad liberadora sobre el olvido"; nunca fugaz o perecedera.

Esto supone resaltar algunas cuestiones esenciales, en un momento de reafirmación y consolidación de la República por tercera vez en Francia, una vez cancelado el Segundo Imperio, después de la humillante derrota de Napoleón III ante Prusia en Sedán el 4 de septiembre de 1870; capítulo que conlleva la pérdida de Alsacia y Lorena. Situación que hubo de afrontarse con espíritu cívico, como era el deber de afirmarse en la línea de las responsabilidades mediante el sacrificio de los intereses particulares ante la comunidad. En cambio esto no fue posible hasta alcanzar el momento en que la nueva República quedara definitivamente instalada el 30 de enero de 1879 , en contrapunto a la falsa república de Thiers (1871-1873) y de Mac-Mahon (18731879). Obvio es decir que, superados esos nueve años, el cometido decisivo de los republicanos moderados conquistaron los votos de los ciudadanos para constituir la mayoría parlamentaria y obtener por votación las leyes que habrían de asegurar las libertades fundamentales, para ver cumplida la realidad de ser libres en el empleo de las facultades mentales y en los hechos asociados a las acciones notables, lo que impuso librarse de tradiciones y convencionalismos. En este contexto, es probable que resulten imprescindibles las palabras de Diderot, por cuanto fueron ideas muy claras y reglamentadas desde una posición de búsqueda: "instruir a una nación, es también civilizarla". Y si se trata de reconstruir una sociedad sobre nuevas bases, las libertades son esenciales para que civilización, amor al saber y democracia permanezcan inseparables y no resulten vacías de sentido.

En este contexto, se entenderá mejor la realidad demostrada por Rodin, los pintores impresionistas, la propia música de Debussy... La percepción del proceso escultórico de Auguste Rodin manifiesta un cambio indiscutible con las expresiones de las posturas tradicionalistas (los dogmatismos de la escuela académica), procediendo, por una parte, a ecos (nunca referencias serviles) del arte greco-romano para poner en un juego de correspondencias con sus búsquedas. Pero en este escultor que metamorfoseó el equilibrio en tensión, para lograr los gestos tensos y privilegiaba la contorsión violenta, fue notable su estudio de la experiencia de las obras de Miguel Ángel, durante su estancia en Italia, donde habrá de explayarse su genio para sacar a la escultura de su entumecimiento y lograr un arte-vivo, en su configuración tridimensional. Es decir, es necesario el contacto directo con el día y la hora, lo que otorga movimiento, luz y color. Tres factores determinantes para experimentar la obra en el espacio real y convertirla en obra no museable.

Esta apertura hacia la modernidad, supone la sinestesia o conexión cerebral específica entre forma, actitudes y movimientos, luz y color, sonido y armonía. Cruce que marca una imagen de palpitación vital. Así su Puerta del infierno (obra sin rematar y encargada en 1880), como también los Burgueses de Calais (conjunto iniciado en 1884/1885 e inaugurado el 3 de junio de 1895), a manera de ejemplos, suscitan un vínculo con la visión romántica de aquel s. XIX. Ahora bien, cada una de estas obras estaba endeudada con la literatura (Dante, Virgilio, Baudelaire, J. Le Bel, J. Froissart) y, sobre todo, realizaba un cambio indiscutible en la interpretación totalitaria de la figura humana al orientar la escultura hacia nuevos horizontes. Y si cierto era que reconocía "no haber aprendido la escultura en las academias", su amplia experiencia en la visita a museos le permitía confirmar "He oscilado mi vida entre las grandes tendencias de la estatuaria, entre la concepción de Fidias y la de Miguel Ángel". Perspectiva que no abarcaría la realidad total si se omite que, este heredero de los grandes románticos, también relaciona su experiencia y conocimiento con el mundo gótico.

Además de estos logros, ¿cuáles eran sus pautas de investigación y las ideas a las que suele ajustar la visión de sus realizaciones? Si se considera su propia manifestación, 
soy cazador de la verdad y observador de la vida. Me abstengo de imitar la realidad. Presto atención a cuanto averiguo en la existencia (el vivir), pero yo no soy quien asigna, es el sentimiento quien influye en mi visión. Pero el artista no percibe la verdad como ella se muestra al común de los mortales, puesto que su emoción le revela la verdad interior bajo las apariencias, mientras que el mediocre mira sin ver.

La nación quedaba por consiguiente entre 1880 y 1920 asentada sobre los valores que habrían de contribuir al enraizamiento de la nueva República; pautas que además de suponer una defensa del laicismo, el sufragio universal y, en especial, los derechos y deberes del ciudadano, precisan la divisa que resume la República: la libertad y la igualdad. Esto suponía una atención importante a propuestas contenidas en la declaración de los derechos del hombre y del ciudadano (la libertad y la igualdad como derechos naturales) de aquel 1789, y que el 17 de junio de 1889 Jules Ferry resaltaba al cumplirse el centenario de la Revolución Francesa. Esto conduce a hacer mención de algunos de los nuevos ideales alcanzados en esta sociedad distinta, rejuvenecida, para comprender los seguimientos sobre los cambios experimentados en los principios artísticos. Según quedaba indicado con anterioridad, los pintores impresionistas y Auguste Rodin, quien en 1880 tenía en su haber La Edad de Bronce, Juan Bautista predicando, obtenía la mención honorable del Salón de Artistas Franceses y, además, el encargo de La Puerta del Infierno, comenzaba a manifestar obras en las que su lenguaje se ajustaba a la experiencia del arte escultórico (sculpturam). Y así, abandonando el arte estatuario (statuam) mantiene relaciones vitales con un valor dinámico determinante al experimentar superficies móviles, llegado el momento de capturar la vida mediante la "expresión completa de los perfiles" ${ }^{3}$ y las posibilidades del movimiento que se revelan bajo las superficies sometidas a la influencia luz-sombra. Condición reservada para determinar una imagen dinámica, de realismo virtual. Así, en cada uno de los Burgueses, tanto el aire, como la luz, como las sombras, aligeran con este efecto combinado la materia frente a la fuerza de la gravedad, conforme señala Hans Joachim Albrecht ${ }^{4}$. Siempre sin olvidar la experiencia creada -como indica varias veces este autor- por el efecto "inconmensurabilidad del bosque", percepción sensorial que prolonga un concepto manifiesto en su momento por el propio Auguste Rodin 5 .

El proceso escultórico de Rodin, tanto en los organismos corporales conjuntos como en las obras carentes de algún miembro, ponía de manifiesto a un modelador nato, cuya materia preferida era la arcilla o la cera, que era posteriormente trasladada al bronce; en una última etapa pasaría a producir obras en mármol, con superficies quebradas y sans fini en las que la luz y el conjunto de sombras y reflejos manifiestan el sentimiento de un movimiento virtual. Habrá de ser el grupo monumental de Los Burgueses de Calais (Fig. 1) el que permite enmarcar las búsquedas y alargamientos pulsatorios de una nueva interpretación de las antiguas tradiciones, interesándose por dotarlas de resultados más óptimos, pero siempre en conexión con el espíritu de su tiempo. De esta aportación saldrán exploraciones que habrán de derivar hacia nuevos descubrimientos; es decir, hacia una escultura liberada de convenciones. Todavía en el homenaje a Rodin correspondiente al año 1954, Constantin Brancusi declaraba: "después de Miguel Ángel, los escultores desearon hacer (piezas) grandiosas, no lograron hacer más que grandilocuencias. En el siglo XIX, la situación de la escultura era desesperada. Llega Rodin y transforma todo. Gracias a él, el hombre vuelve a ser la escala, el módulo, la proporción, se vuelve a organizar la obra. Gracias a él la escultura se vuelve humana en sus dimensiones y en la significación de su contenido" 6 .

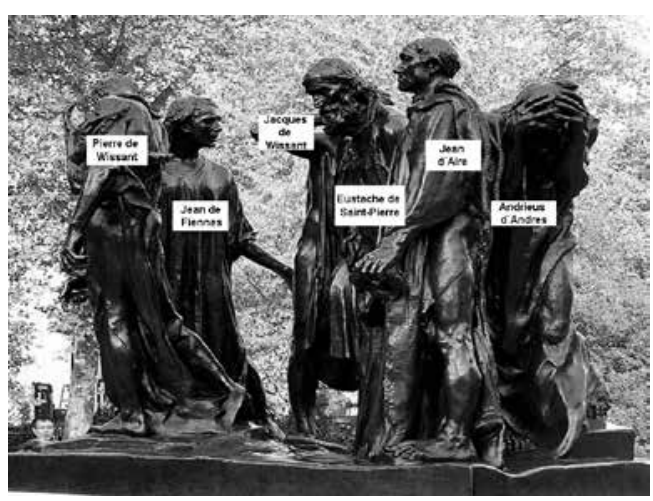

Fig. 1 Los Burgueses de Calais (1885-1895). París, Museo Rodin. 
En realidad los hallazgos que dan a su obra nuevas perspectivas, de igual modo que un nuevo punto de arranque que rebasa los límites expuestos por Adolf von Hildebrandt, no solo vienen marcados por la consolidación de puntos de vista artísticos diferentes: "para Hildebrandt, todo lo tridimensional está reducido a características planas, para Rodin la concepción es opuesta al considerar las distintas posibilidades de las imágenes dinámicas"7. Y no sorprende, ante las amplias interpretaciones que fueron expuestas sobre las múltiples contribuciones de Rodin con una visión renovada de la escultura, así la que tuvo su entrada en escena en el siglo XX con las llamadas "figuras que caminan" de Alberto Giacometti y, sobre todo, captar los componentes del movimiento en el espacio de la realidad allí "en el lugar donde transitan hombres y mujeres; tal es la comparación establecida de este deseo de Giacometti en su Caminante // (1960) para una plaza pública de Manhattan, con los deseos manifestados por Rodin de ubicar Los Ciudadanos de Calais en un área urbana entre transeúntes"8.

Los hallazgos de Rodin, su cambio radical de tradiciones y costumbres, sin duda estuvieron alentados en sus inicios por Antoine Louis Barye y Constant Simon, quienes le aconsejaron estudiar el dentro-fuera, auscultando desde distintos ángulos y posiciones; como también $\mathrm{M}$. Carrier-Belleuse, con quien se inscribiría como discípulo en los catálogos del Salón, donde él y los pintores impresionistas necesitaban ir ligados a sus maestros para ser acogidos ${ }^{9}$. Pero existe un trabajo de Robert A. Sobieszek que toma como referencia aspectos de la conversación de Dujardin-Beaumetz con Rodin donde se describe el método que poseía Rodin de modelar las figuras desde una multiplicidad de perfiles tomando como referencia el modelo o modelos, las fotografías, como también un referente nuevo en el mundo del arte parisino que era la fotoescultura, cuyo inventor fue François Willème. Este proceso consistía en la construcción del retrato-escultura en tres dimensiones, usando perfiles fotográficos que, tomados de posiciones consecutivas, se elaboraban rodeando el modelo o modelos. Tales perfiles habrían de ser transformados en una matriz de tres dimensiones, de la cual se hacía un molde y se fundía la estatua terminada o casi terminada. El desarrollo se basaba en la idea de que la suma de todos sus perfiles daba el total volumétrico.

Cierto es que nunca dicho proceso se ha relacionado con los métodos de trabajo de Rodin, sin embargo para el artista las distintas posturas y actitudes del cuerpo eran creadas a partir de los propios perfiles. Para ello hacía girar al modelo o modelos, tal como se recoge en las múltiples fotografías hechas para Los Burgueses de Calais, observando los contornos y subiendo y bajando una escalera para obtener distintos puntos de vista. Mediante este proceso Rodin estaba haciendo uso de una construcción basada en la observación, en lo que había de ser su creación de imagen en plein air. Se llegaba así, tal como dice A. E. Elsen, a "capturar la vida por la expresión completa de los perfiles" 10 .

Son muchos los componentes a considerar en la biografía de Rodin, pero con fuerza excepcional está presente en su labor lo que se podía denominar un despliegue positivista; ley del que procura alcanzar el rédito de las ventajas del presente sin abdicar de su convicción en la evolución y el progreso. Esto se comprenderá mejor si se pone de manifiesto que su labor fue un combate por la renovación de la escultura en solitario, a la vez que los impresionistas formaban un grupo para llevar adelante sus ideas ${ }^{11}$.

Alguien tan acostumbrado a conseguir la penetración psicológica en sus pinturas al óleo como Jacques-Émile Blanche (1861-1941), en su obra consagrada a Rodin toma medida inmediata del efecto telúrico de la mirada indagatoria y entreabierta de este escultor, mientras en paralelo sus manos se apoyan con fuerza sobre un grueso volumen (Retrato de Auguste Rodin, óleo sobre lienzo, 1904. Paris, Museo Rodin (Fig. 2). El significado inmediato del cuadro se percibe en la propia manifestación del retratista sobre Rodin: "este no es un escultor, es un profeta". Aunque resta mucho por hacer sobre lo que fue la obra de este pintor, la reciente exposición celebrada en París (octubre de 2012-27 de enero de 2013$)^{12}$ contribuye a restituir lo que fue el tono de una época en Francia y con ella la gran panorámica de la prosperidad, la expansión político-colonial, justificada por la misión civilizadora de la República como portadora de los 


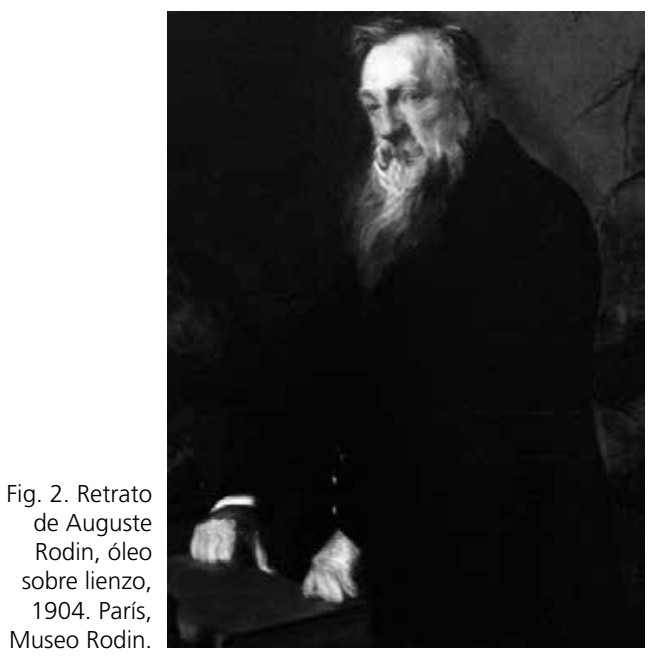

ideales de la Gran Revolución, a la que se une la labor creativa literaria y los planteamientos relacionados con la configuración artística.

La mejor demostración del prestigio de sus valores culturales en Europa queda establecida por las grandes exposiciones universales, la construcción de la Tour Eiffel (1888-1889), el primer aniversario de la Revolución Francesa (17 de junio de 1889), la celebración del centenario de la República (1792-1892)... Y en cuanto a Rodin, era el momento en que, como decía en su obra Las catedrales de Francia, "para mis contemporáneos yo soy un puente que une las dos orillas, el pasado y el presente". Se podría decir que era conciliador y profético, puesto que había renovado las grandes tradiciones perdidas, y al propio tiempo confiere una interpretación interesándose por ellas y ligándolas al espíritu de la época. Y es que tanto Rodin como sus compañeros y amigos Monet, Renoir o Cézanne, entre otros, estaban demostrando que cada uno en su campo eran los auténticos continuadores de las obras y de las teorías del pasado. Cuando en 1875 viaja a Reims, Ginebra, Lausana, Génova, Pisa, Florencia y Roma, no duda en reconocer que es el momento que considera fundamental, puesto que descubre el gótico; a Puget, el escultor cantado por Baudelaire, en Génova; pero sobre todo a Donatello y a Miguel Ángel que, como él mismo reconoce, le ayudan a liberarse de los estigmas de la escultura académica.
Habría que decir sin embargo que el realismo de la anatomía consustancial con los animales de lucha, de presa, salvajes, de Antoine-Louis Barye se encuentran en las torsiones corporales de ritmos inesperados, flexiones imprevistas, la originalidad perturbadora de todas las posiciones, de las figuras arqueadas y dobladas de LoS Burgueses de Calais. Ahora bien, cierto es que como él mismo dice, muchas de las percepciones aplicadas surgen de la contemplación de los árboles del bosque, del mundo gótico, así como de la comentada escultura como suma de perfiles. Todo ello deriva hacia una brutalidad humana donde los movimientos corporales, señala Jean-Marie Moeglin, son más coreográficos que teatrales ${ }^{13}$, pero no desacordes. Hay un dominio del código o comportamiento kinésico, donde el lenguaje corporal expresa resultados emocionales o anímicos del momento, puesto que la condición humana también se expresa por el movimiento de las articulaciones y músculos. En palabras del propio A. Rodin, "resulta extraño que yo represente el reposo completo, puesto que siempre intenté dar cuenta de los sentimientos interiores por la movilidad de los músculos. $Y$ es que el arte no existe sin vida...y tal concepción se obtiene por el buen modelado y el movimiento. Atributos que son como la sangre y la respiración de todas las obras bellas" (Auguste Rodin, L'Art, entretiens réunis par Paul Gsell, Chap.IV Le mouvement dans I'Art). Así el autor del Caminante acéfalo y manco, rehusaba asimismo el movimiento congelado al evaluar el ritmo en la escultura, puesto que en toda obra que palpita vida, existe un cambio de pose (decía) que es el resultado de la evolución entre dos equilibrios. Cabe referirse al burgués Pierre de Wissant (Fig. 3) como ejemplo que verifica momentos sucesivos sobre el movimiento y la verdad, toda vez que en la realidad, comenta Rodin, el tiempo no se detiene y si el artista acierta a reproducir la impresión de un gesto que transcurre en varios momentos, su obra es menos convencional que la fotografía donde el tiempo queda suspendido.

Pierre de Wissant fue concebido por Rodin y su equipo para una disposición frontal: "mis estatuas las unas detrás de las otras". Ejemplifica muy bien como las emociones y las interpretaciones del movimiento no muestran repercu- 


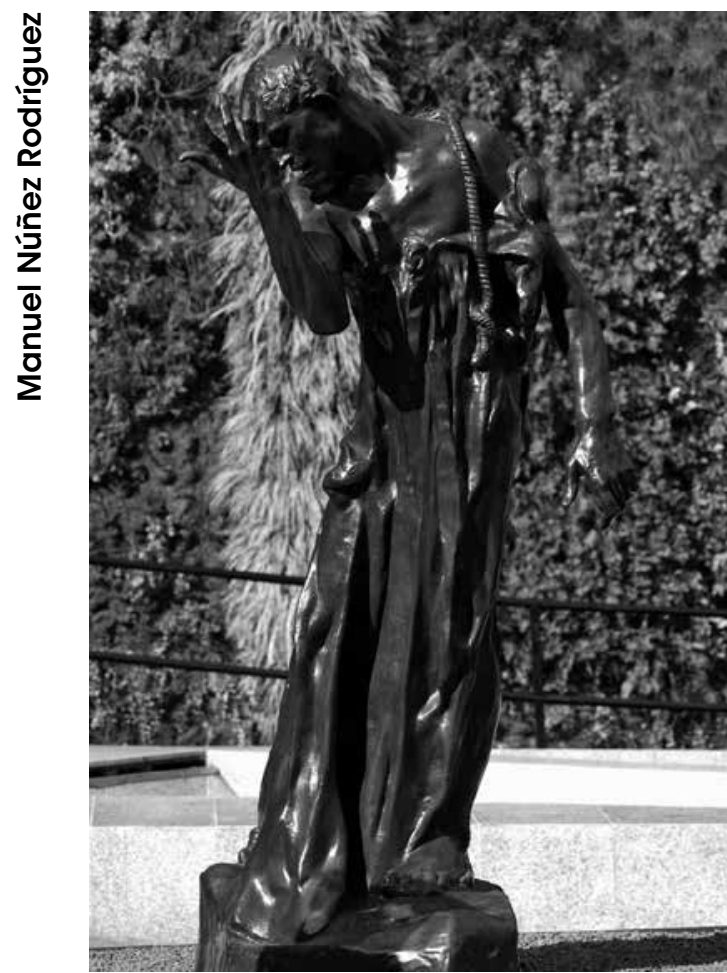

Fig. 3. Pierre de Wissant (Burgueses de Calais). París, Museo Rodin.

siones de la fotografía, donde el tiempo queda detenido. Por el contrario, aquí el lenguaje emocional reúne en una sola composición los más expresivos gestos de alteración aguda, rabia, desesperación..., para transmitir al observador las diferentes fases de un ritual de harmiscara generado como una iconografía de humillación y ejecución simbólica.

Gran conocedor de la anatomía humana y del desarrollo de la autoexpresión, el denominador común al que reduce todo cuanto percibe, para unificarlo y conferirle la estudiada elocuencia de los gestos y movimientos corporales, procura dar cuenta para plantear el cuerpo como la naturaleza compone y no como la anatomía describe. Así la detallada mano in pronazione (Fig. 4). Con el dorso girado, expresa un estado emotivo de dolor y desesperación. Se diría que existen en ese contorno neto y exigente puntos comunes con el Greco; con el código, el contenido y la forma de las manos consustanciales con este pintor.

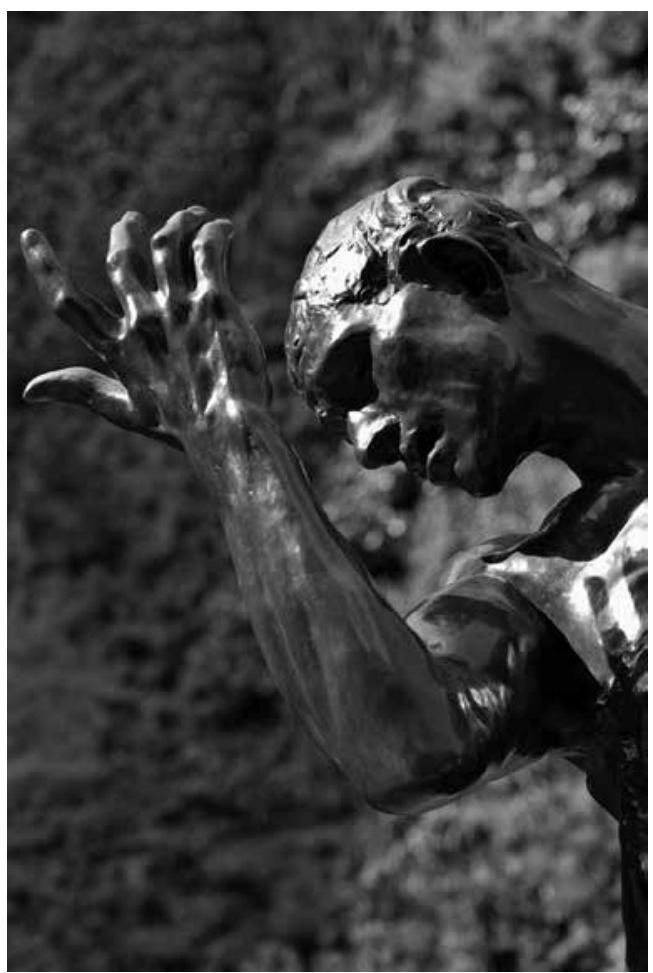

Fig. 4. Pierre de Wissant (detalle). París, Museo Rodin.

Atribuidas a Camille Claudel, como el elaborado estudio de la expresión facial, la característica más destacada del rostro es el estado emocional del momento; en otras palabras, el concepto sobre el drama humano ante la muerte en solitario. La frente, cejas, ojos, nariz, mejillas, boca, mentón, conforman el comportamiento kinésico, junto con la inclinada cabeza, el brazo alzado y el busto hacia delante. De todos modos, el poder de sugerir movimiento sin ruptura es determinante por los gestos y la diagonal heroica del torso; postura revelada en el Esclavo Moribundo de Miguel Ángel (mármol, Museo del Louvre). Posibilidades comparativas del pathos expresadas por J. Polzer ${ }^{14}$. Una vez más, se pone como manifiesto que "el arte sólo puede conmovernos sí, por principio sabe hacer vivir cuanto evoca".

Sin duda se impone señalar un dato de alcance capital antes de proseguir. Aquí no se pretende una valoración detallada de una obra tan conocida como los Burgueses de Calais (Fig. 1), 
puesto que supondría incidir en cuestiones planteadas. Sólo tomaré como prueba aquellos aspectos reservados y decisivos en Jean-Marie Moeglin en dos trabajos ${ }^{15}$. En ellos podemos aproximarnos a los posibles hechos, a partir de las crónicas de Jean Le Bel, escritas en los años 1352-1361, así como las crónicas de Froissart. No hay necesidad de insistir sobre el alcance de esta comprobación que constituyó la respuesta a la obra de Rodin, sobre el momento en que el monarca inglés Eduardo III, renunciando al consejo de sus barones, hace venir a los defensores de Calais después del asedio que durante un año había sufrido la plaza.

Conforme a Jean Le Bel, el primer varón en acudir fue Eustache de Saint-Pierre, quien dice a los demás habitantes:

señores yo creo que para la defensa de la villa es mejor la muerte y así obtener el perdón de mis faltas, y yo quiero ser el primero en presentarme con los pies desnudos, vestido con una camisa, la soga de esparto al cuello y alcanzar la merced del rey Eduardo.

Conforme la crónica de Jean Le Bel, el ejemplo de Eustaquio es seguido por los otros cinco burgueses: "no es necesario decir -añade el cronista- que todos los demás hicieron la voluntad del rey Eduardo para así salvar el remanente del pueblo". La puesta en escena es simbólica, y si cierto es que Jean Le Bel no recoge el nombre de los restantes burgueses, será Froissart quien lo especifique.

Pero aquí cabe una observación: si conforme a las crónicas los burgueses no quedan sometidas al holocausto del soberano, puesto que en último recurso la reina Philippa de Hainaud finalmente intercede ante el rey por ellos y alcanzan su misericordia, también es cierto que este autor, Jean-Marie Moeglin, añade una interpretación que se podía denominar como la explicación de la historia de una capitulación, la de los Burgueses de Calais, pero sin condena. Es decir, había una solución que era someter a lo que se denominaba "un rito humillante de ejecución simbólica, a cambio del cual estaba la garantía de salvar la vida". Era lo que se conocía como rito de harmiscara o de humillación pública. Ceremonia que conllevaba un pacto y un perdón o gracia a la vida. Era frecuente en Francia, en
Italia y en Alemania en los años del medievo. En este sentido, el propio J.-M. Moeglin recuerda que la capitulación de Calais de 1347 constata concordancias con Cremona y Brescia en 1311. ¿Cuál es, entonces, el concepto básico de este rito de harmiscara?; según parece, los afectados se revisten con el hábito asociado con la acción penitencial, de manera especial los condenados a muerte, si se consideran las exigencias del ritual judiciario, conforme a las explicaciones de Jean-Marie Moeglin. Luego, complementariamente, habrán de quedar al descubierto los pies, la cabeza, y en camisa. En cuanto a la cuerda al cuello, es la señal de quienes merecen ser colgados. Ahora bien, puesto que en el caso presente se sometieron a rendición, y entregaron las llaves de la villa al vencedor (es decir, el monarca inglés), demostraron una capitulación sin condiciones. En consecuencia, Eduardo III, a su pesar, experimenta su clemencia el 4 de agosto-1347.

Entonces, lo que Rodin recuerda es, teóricamente, un planteamiento de humillación pública a través de un ritual de ejecución simbólica pro patria. Ahora bien, hay que tener en cuenta que la III República, como dice Mona Ozouf, "no tiene héroes para honrar", de manera que cuanto aquí quedó planteado no justifica a seres que merezcan honores públicos, puesto que lo que buscaba Rodin era disponer a sus personajes unos detrás de los otros sobre los enlosados, de manera que los habitantes participarían hombro con hombro de un principio de solidaridad con los cinco burgueses. Esto explica su deseo por visualizar, según sus propias palabras, "mis figuras, las unas detrás de las otras, ante el ayuntamiento de Calais, en las mismas losas del lugar, como una secuencia viviente de sufrimiento y de sacrificio". Es decir, estaba haciendo referencia a una composición encadenada, sin capturar el espacio que actualmente repliega a las esculturas. "Pero mi proyecto fue rechazado y se me impuso un pedestal tan desgraciado como superfluo"16. Cuando la Revolución no exalta.

El valor representativo de este conjunto escultórico, donde la base o pedestal se rechaza, anuncia el puesto que ocupa el reposo del conjunto como una verdadera arquitectura que parece descansar sobre la superficie del suelo, de 
manera que Rodin, al colocar el grupo de figuras de Los Ciudadanos de Calais a ras de tierra entre los habitantes de la ciudad, aunque en principio ni su puesta en escena ni el pedestal añadido respetaran su proyecto, en realidad estaba anunciando un propósito con valor de futuro en la escultura. Y así, como apunta Hans Joachim Albrecht, en este conjunto encontramos el primer proyecto novedoso de lo que debe ser la base; es decir, una superficie básica, delgada, para separar el conjunto mínimamente del espectador, pero que no se convierta en un sistema cerrado e independiente ${ }^{17}$.

Antes de proseguir hay dos cuestiones que me parecen importantes. La primera se refiere al autor que le ayudó a obtener el encargo de esta obra. Con frecuencia se dice que el Conseil Municipal de Calais solicita en septiembre de 1884 a varios artistas presentar varios proyectos para la imagen de Eustache de Saint-Pierre. Por supuesto sabido es que la respuesta de Rodin nunca sería la de asumir la representación de una sola figura, por lo que implica de cesarismo, de manera que su esbozo mostrado en diciembre de 1884, seguido de un segundo proyecto en julio de 1885, fue el de seis figuras por el precio de una sola. El Consejo adoptó una decisión favorable, aunque es verdad que imponiendo objeciones a los bocetos presentados. Ahora bien, no hay que olvidar que el personaje que le ayudó a obtener el encargo de esta obra fue Falguière, como manifiesta a Paul Gsell,

Sin duda él no me debe nada, pero su afecto y fidelidad me ayudó a obtener el encargo de Los Burgueses de Calais. Otro tema es que esta obra de seis personajes en bronce fuera propuesta al precio de una sola, pero yo le guardo un reconocimiento profundo por haberme inducido a crear una de mis mejores obras. Por ello, yo he tenido el gran placer de hacer su busto, aunque él me reprochó amigablemente haberle representado con la boca abierta, a lo que yo le respondí que conforme al diseño de su cráneo, él descendía muy probablemente de los antiguos visigodos de España, y que este tipo se caracterizaba por el prognatismo del maxilar inferior. Pero yo no sé si él se da cuenta de esta observación etnográfica ${ }^{18}$.

La otra cuestión queda determinada por dos capítulos que todavía hoy permanecen abiertos o poco definidos. El primero consiste en consi- derar cuál era la propuesta de la ville de Calais en cuanto al recuerdo de quienes constituyen la memoria histórica. En la actualidad se conserva en el Conseil Municipal de Calais una talla de Eustache de Saint-Pierre, uno de los héroes de su historia, elaborada en piedra blanca, con una altura de $41 \mathrm{cms}$., $93 \mathrm{cms}$. de ancho y $74 \mathrm{cms}$. de profundidad. Esta obra corresponde a 1820, en la época de Luis Felipe, y su autor fue J. P. Cortot, escultor neoclásico que remata su trayectoria artística en combinación con la expresión romántica, y que sería elegido para remodelar alguna de las musas de la plaza de la Concordia que evocan cada una de las ciudades francesas. Ahora bien, lo que aquí interesa será que después de 1845, Calais encargará una estatua a David d'Angers sobre Eustache de Saint-Pierre, y aunque la muerte obstaculiza su realización, en 1868 el escultor Clésinger volverá a recibir el mismo cometido. Pero la guerra de 1870 obliga a abandonar tal encomienda. No sorprende por consiguiente que A. Rodin considere la necesidad de presentar un grupo conjunto de seis burgueses que den respuesta al contenido de la crónica y, de esta manera, se pueda anular todo cuanto pudiera sugerir el principio cesarista que conllevaría una figura en solitario.

Rodin por consiguiente evita todo ensalzamiento personal, y con ello lo que signifique sublimación o canto al héroe, puesto que concibe su proyecto bajo la premisa de dos valores: como hombre de una época y también es importante incidir en su relación con un espíritu positivista. El positivismo participa de la valoración de los sucesos o hazañas evidenciados por el propio conocimiento. En términos generales, los preceptos a considerar en torno a lo que se plantea comienzan por evaluar las alegaciones o testimonios recogidos en la crónica de Jean Le Bel y Jean Froissart, como también por la propia Historia. Al mismo tiempo, no puede dejar de otorgarse prioridad a las informaciones que podrán denominarse de primer grado, ya que puede darse un fallo en la veracidad o en la evidencia, por lo que tendrán vigencia aquellas pruebas que equivalen a afirmar en tiempo y lugar los hechos reales a considerar. Por esta razón, resulta explicable que $A$. Rodin hubiera utilizado las crónicas de aquellos dos autores en tanto que fuente capital para comprender la Historia de Francia; de 
manera muy especial la que atañe al episodio de Calais en el siglo XIV (1346-1356). Esto es a propósito de la reciente obra de Voltaire Essai sur les moeurs et l'esprit des nations et sur les principaux faits de l'histoire depuis Charlemagne jusq'à Louis XIII, editada en 1761 y $1785^{19}$, donde al no avanzar ninguna prueba su interpretación fue totalmente ignorada e inexactas sus conclusiones.

Por principio también hay que añadir que Jean-Marie Moeglin hace un recorrido sobre la valoración de los patriotas de Calais y las distintas tesis, tanto en la Historia francesa como inglesa, donde las referencias que existen sobre las consecuencias del asedio no siempre son las mismas; y sin embargo, A. Rodin centró la realidad de la tragedia en las dos crónicas citadas varias veces en el presente trabajo, de manera que es en ellas donde reivindicó, encontró, dio con, descubrió, halló las pruebas a considerar por su veracidad y evidencia. Ahora bien, junto con ellas, su proyecto también pone en valor la divisa de la República, libertad-igualdad-fraternidad; trilogía sobre los valores de un futuro común.

Por consiguiente, si se trata de reconstruir la Historia con sus propios métodos, se impone la importancia de los hechos y rehuir la manipulación. Para ello existían tres maneras de evitarla: considerar sus decisiones sobre la puesta en escena; otra cuestión era crear la función novedosa de la base, de manera que no se trata de añadir un basamento, pero sí un apoyo adicional o superficie delegada que a manera de plinto contribuya a separar el grupo del espacio real del espectador, haciendo posible su contribución como conjunto escultórico propio ${ }^{20}$; finalmente, cierto es que Los Ciudadanos de Calais, para determinada bibliografía, están asociados al ritual de ejecución simbólica pro patriae mori, mediante los pies desnudos, la cuerda al cuello, la camisa humillante como invocación de la desnudez... Los supuestos a invocar son múltiples, pero habrá que otorgar valor a los que estén en consonancia con las concepciones en dos momentos: en el pasado y en el presente. Aunque sin descartar cierta grandeza trágica impregnada del hilo narrativo, de la carga emotiva a causa de la influencia de Las flores del mal de Baudelaire; así Les Épaves (Los Desechos), poemas censura- dos de fuerte inspiración artística, sobre la angustia y la impiedad.

Por principio el grupo, como señala JeanMarie Moeglin, lleva lejos de la exaltación patriótica y aproxima a los rituales de humillación pública, según quedó apuntado en párrafos anteriores. Esta concordancia se produce a través de un ceremonial de ejecución simbólica que esencialmente implica una doble lectura. En efecto, este autor reconoce -como quedó indicado- el ritual de harmiscara; concepto integrado en el medievo en ciertas regiones alemanas, pero también francesas, y que Jean Le Bel y Froissart participarían de su conocimiento. Y así, con los pies desnudos, vestidos con camisa, y la cuerda al cuello, ello no implicaría que fueran ejecutados ni colgados, sí por el contrario sometidos a un acto de humillación seguido del consiguiente acto de contrición ${ }^{21}$. La pregunta es: ¿participaba A. Rodin del conocimiento del derecho jurídico medieval? También es verdad que Jean Le Bel señala que en el momento que los seis burgueses fueron liberados de la ruina por el "amor de la reina inglesa, la buena dama hace vestir y asear a los dichos seis burgueses" 22 . Esto supone que Eduardo III era la encarnación del ideal caballeresco, puesto que tenía marcado como objetivo un acto de castigo, del que no hace empleo tras la capitulación de los habitantes de la villa. De manera que cuanto se pone en escena implica más los prolegómenos de una ejecución simbólica previa al empleo de la ética de la justicia, que del capítulo anterior a una ejecución real.

Uno de los cimientos que favoreció la formación del ciudadano y la vitalidad de la práctica democrática fueron los alcances de las libertades, del espíritu crítico, como también del espíritu cívico que, para lograr una sociedad más humana, suponía no abdicar del espíritu de inclinación hacia los intereses de la comunidad. Según reconocía Paul Bert, en este momento: "si os olvidáis de uno de estos tres términos indisociables, el espíritu de la República no va adelante. Sin la libertad, la igualdad puede ser la más abominable de las esclavitudes, pues todo el mundo es igual bajo un tirano. Sin la fraternidad, la libertad conduce al egoísmo". Pero pronto la fraternidad sería suplantada por la solidari- 
dad, lo que equivalía a purgar sus connotaciones cristianas cuando en el año 1905 se produce la separación Iglesia-Estado ${ }^{23}$.

Ahora bien, se impone recordar a Jules Ferry, ministro de Instrucción en el origen de la educación cívica y moral, para formación del hombre y del ciudadano. En su interés por establecer una enseñanza primaria gratuita y obligatoria de métodos pedagógicos, su finalidad era ante todo la instrucción, puesto que buscaba alentar la autoformación. Por consiguiente, la argumentación de este ministro era taxativa: se trata de formar conciencias, y esto tiene un principio claramente evidente, pues era el mejor modo de "reforzar el sentimiento de la comunidad francesa". Esta mención no puede pasar desapercibida. Cierto es que la finalidad de la educación pública y laica, junto con la libertad de prensa, libertad de reunión, la autorización del divorcio...., definen en la actualidad a Jules Ferry entre los personajes más positivos del panteón francés como "el reformista que intenta consagrar todo su combate político para consolidar la victoria de la democracia en aquella III República, con la finalidad de reconciliar las dos Francias (en principio el laicismo es un combate contra la Iglesia), pero también de asegurar la cohesión nacional tras las recordadas pérdidas de Alsacia y Lorena, así como las diferencias entre paisanos y burgueses, aliados de la derecha clerical, monárquicos bonapartistas herederos del jacobinismo..."24.

Llegados a este punto se impone recordar que tanto A. Rodin (1840-1917) como su contemporáneo Jules Ferry (1832-1893, muerto por atentado) ejemplificaban "la bestia negra para la derecha conservadora y radical" (J. M. Gaillard). Sobre Rodin existen muchas teorías a rebatir; aquí es suficiente con señalar interpretaciones que no contribuyan a ampliar el tono polémico, puesto que fue suficiente la actitud adoptada por la propia prensa de la época, jornales con declaraciones de sus adversarios, que constituyeron una muestra penosa de las violentas campañas por parte de colectivos defensores del cometido de las reglas académicas y, en consecuencia, contrarios al criterio de quien fue un paladín de la conciencia libre. Cuestión que pone de manifiesto una pregunta: su admirable y resaltada obra El Pensador (Fig. 5), ¿hasta qué punto no convertía en reflexión lo que el propio Rodin afirmaba sobre su asociación con el sufrimiento humano? Además, quien se hizo especialmente receptivo a los planteamientos filosóficos de Friedrich Nietzsche, como su amigo Edgard Munch, ¿no estaba experimentando con la imagen plástica de un hombre nuevo que convertía al hombre clásico en muerto, como los dioses de Nietzsche? ${ }^{25}$ Bastaría con recordar los años de la Belle Époque, la Exposición Universal de 1900 como factor que configuró su imagen como padre de la escultura moderna.

Pero su oficio invita a convertir tal ejercicio en una reflexión, a manera de problema todavía sin resolver. Así, las operaciones en esculturas de mármol, son proyectos concebidos en bloques en los que la parte inacabada surge sumariamente desbastada. Formas de experiencia que enmarcan las secuencias rítmicas de La Danaide (Fig. 6) entre la base del prisma (non finis) y el modelado del cuerpo (finis). Experiencia que lleva a considerar, como advirtió Rodin: "me contento con dejar a la modelo maniobrar a su manera; toda actitud impuesta no es natural, puesto que

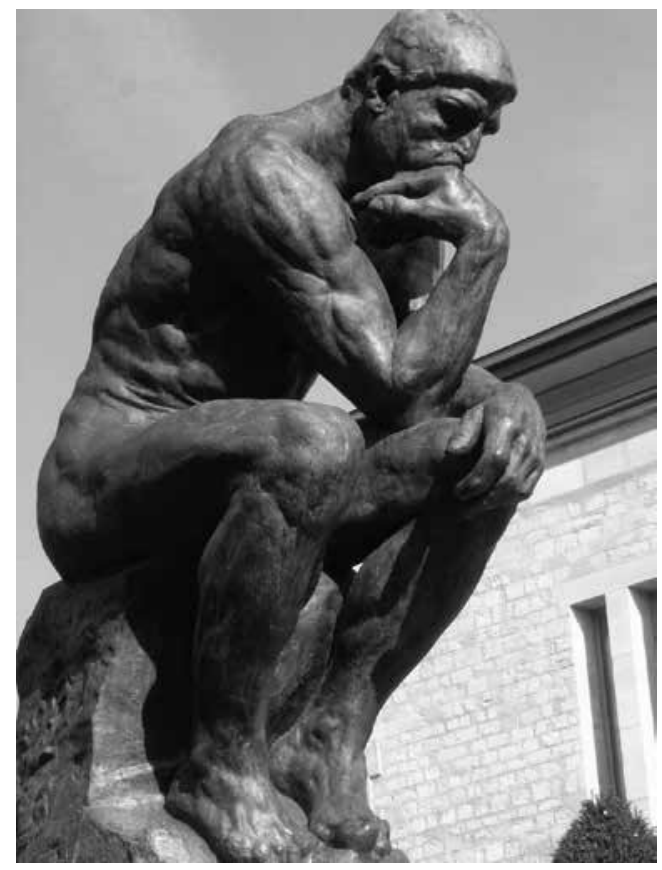

Fig. 5. El Pensador (1880. Debería formar parte de la Puerta del Infierno; hoy, una copia en la tumba de Rodin en Meudon). París, Museo Rodin. 


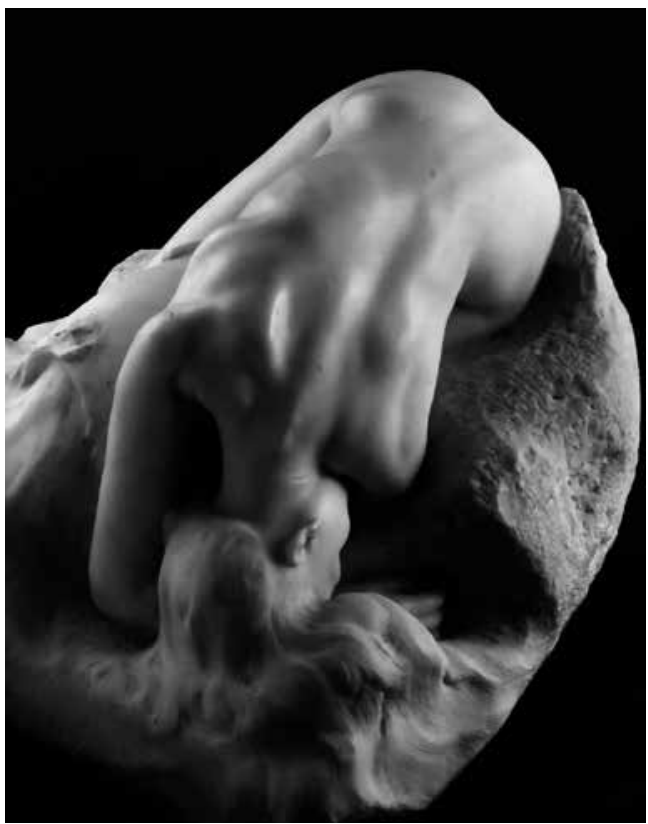

Fig. 6. Danaide (en origen en la Puerta del Infierno, 1885 y 1889). París, Museo Rodin.

es reemplazar lo ilimitado, infinito, por lo limitado" (Paul Gsell). Consecuentemente, la fuerza generadora de La Danaide (1885 y 1889) (Fig. 7) no es unívoca y definitiva ante el espectador. En cierto modo se metamorfosea, no adopta una posición de reposo total y nos traslada a un espacio infinito, donde los contornos son partes en movilidad, bajo sombras desdibujadas. En cuanto al movimiento, está constituido por secuencias rítmicas. En definitiva, La Danaide hace alusión a una referencia simbolista y mitológica,

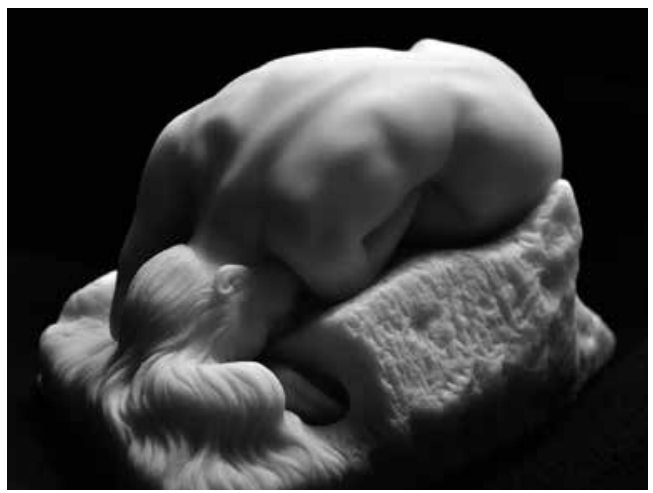

Fig. 7. Danaide (1885 y 1889). París, Museo Rodin. aplicada a las cincuenta hijas de Dánao, hermano de Egipto, quien se vio obligado a emigrar a Libia con sus hijas, esforzándose las Danaides a llenar de agua una crátera sin fondo en un vano intento de purificarse ${ }^{26}$. Es de resaltar el efecto lustral de la cabellera invocando una aproximación al Art Nouveau. Se considera una de las obras de erotismo más sublimado por la postura reclinada con el rostro oculto en el mármol. Rilke estimaba que "con gran sollozo, aun hablaba en voz baja el corazón de los hielos eternos del bloque". La belleza se exhibe por la forma física y triunfa la rotundidad de la silueta, toda vez que Rodin evita el "estilo canalla pues no es bella el alma viciada".

Así, desde La Edad de Bronce, Juan Bautista, El gigante acéfalo y manco, Los Ciudadanos de Calais, El Pensador..., se ponen de manifiesto las facultades inventivas de un escultor que tuvo que asumir el riesgo de las críticas aceradas por evitar la sequedad del modelado académico .El cuerpo queda evaluado como la naturaleza compone, ya que el incesante cambio del tiempo determina efectos como la decrepitud y la sombría meditación de La anciana Heaulmiére (Fig. 8). Esto no contradice su ejercicio mental:

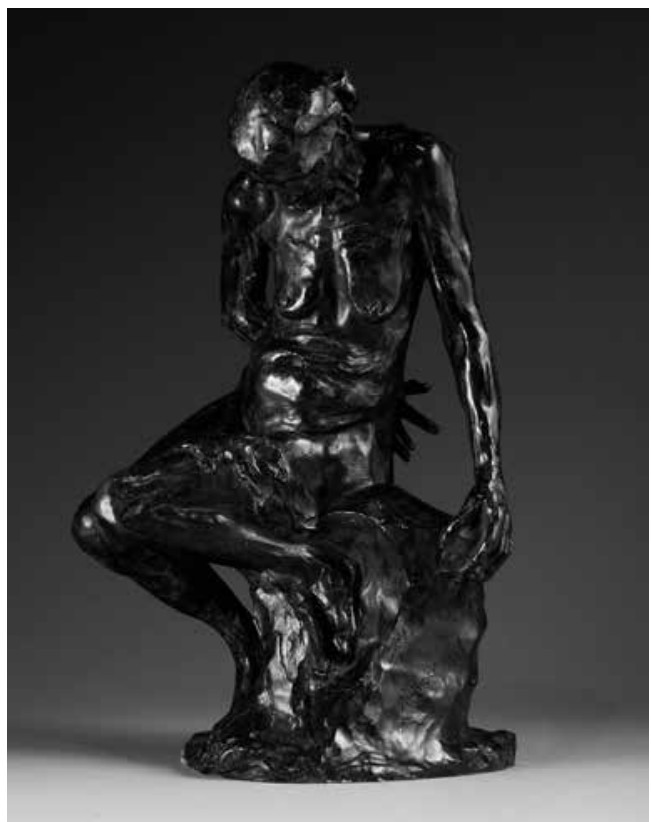

Fig. 8. La vieille Heaulmière (Puerta del Infierno, 1894). París, Museo Rodin. 
"iQue me digan si he cometido alguna falta de anatomía!". De esta manera, todas las obras antedichas comunican tal fuerza de expresión que, a la vez que caracterizan a la piel de un cuerpo en acción vital, una obra como la Edad de Bronce hoy marca distancia con lo que fue una actitud de inculpación sin criterio, al acusarle de haber logrado "tal perceptibilidad asociada a la palpitación del efecto vida" mediante el modelado del joven cuerpo. Cierto fue que al poco tiempo, en 1880, la compra de dicha obra por el Estado demostró hasta qué punto las acusaciones carecían de fundamento.

El redescubrimiento de Joseph Polzer en torno a los precedentes de La Edad de Bronce reenvía a un contacto directo con la obra el Esclavo moribundo de Miguel Ángel. Asimismo, acompaña este planteamiento una obligada referencia a la figura de Adán adormecido con la cabeza apoyada sobre el hombro izquierdo en La Creación de Eva (Capilla Sixtina del Vaticano); como también es verdad que no pasa por alto la imagen del Día en la tumba de Julián de Medicis, obra de Miguel Ángel en San Lorenzo de Florencia. Planteamientos caracterizados todos ellos por rehuir los convencionalismos académicos, y donde tanto el contenido psíquico como físico de la imagen se concentran en el interior para insinuarse bajo la piel, lo que supone una manifestación de las distintas superficies.

Junto a lo dicho, hay que apuntar aquello que para Rodin resultaba básico: "El arte no existe sin vida. Que una escultura busque interpretar la alegría, el dolor, la pasión, o cualquier manifestación, no puede ser posible si en principio no se sabe hacer vivir a todos los seres que un escultor evoca. ¿Pues, qué sería para nosotros la alegría o el dolor de un objeto inerte llevado a un bloque de piedra? Esto supone que la ilusión de vida se obtiene mediante el buen modelado y el movimiento. Dos cualidades que son como la sangre y el soplo de vida de todas las buenas obras. De manera que solo pueden conmovernos aquellas esculturas que por principio saben hacer vivir" ${ }^{27}$.

Por consiguiente, tanto El Pensador como La Edad de Bronce o Los Ciudadanos de Calais entre otros, representan un avance sobre lo que Rodin reconocía como una negativa al re- poso en beneficio del valor de la animación, de la representación de obras vivas, de propuestas que palpitan y respiran sentimientos interiores, puesto que el movimiento es la transición de una actitud a otra, es el paso "de lo que fue a lo que va a ser". Este paso de una actitud a otra, esta demostración de las manifestaciones emotivas, de lo que es transición, obligan al espectador a verificar en toda obra el efecto de los brazos, de las extremidades inferiores, de las manos..., de todo cuanto contribuya a definir la movilidad en el tiempo.

Pero sin duda, del conjunto de obras de Rodin, El Pensador alcanza un interés particular, no en vano existe un ejemplo dispuesto sobre su tumba en la Villa des Brillants, que simboliza el espíritu creador de Rodin. En cuanto a su importancia no se podría disociar de la reflexión de Rodin y evaluarla conforme a su propia referencia: "Lo que hace que mi Pensador piense es que él piensa no solo con su cerebro, con sus cejas fruncidas, sus narices dilatadas y sus labios apretados, sino también con cada músculo de sus brazos, con sus espaldas y sus piernas, con su puño cerrado y sus dedos crispados" 28 .

Según Joseph Polzer ${ }^{29}$, la elaboración de La Edad de Bronce coincidía con los años en que Rodin llevaba a cabo El Pensador. En otras palabras, eran momentos de una actitud en la que Rodin todavía no había llegado a conquistar la fama y a marcar una etapa de la escultura, la que le llevaría a morir como un artista célebre en 1917. Ambas obras por el contrario corresponden al entorno de los años 1880; es decir, cuando la imagen del joven soldado Auguste Neyt era considerada como resultado de un moldeado a partir del natural. Sin embargo, por aquel entonces captaba su atención la visita a los museos, los efectos indagados en la escultura de Miguel Ángel y la asimilación de su experiencia tras su estancia en Italia en 1875.

Como aspecto clave entre Miguel Ángel y Rodin, Joseph Polzer, al mismo tiempo que entonaba una actividad creativa sobre EI Pensador, donde la idea clásica entra en contradicción con un principio romántico (conforme a J. Polzer, en tal planteamiento "el pensamiento es transmitido desde el espíritu hasta los sentidos y se vuelve aparente a través de la actividad muscular; 
transferencia imposible de evaluar en la concepción clásica, quien opone la elevación del pensamiento a los sentidos, puesto que en la tradición clásica el pensamiento es simbolizado por la asociación de la mirada y de una actitud meditativa" $)^{30}$. De una generación a otra, si cierto es que determinados valores son cambiantes como la sociedad, sin embargo el Pensador encara una prueba que parece concluyente, y es que Rodin no dudaba en asociarlo al hombre que sufre; por consiguiente, al concepto del dolor humano. $Y$ todo ello en un momento de plena crisis laboral, atentados anarquistas, cuestiones que plantean el concepto de la tragedia humana frente al destino. Cuanto se ha dicho hasta aquí supone volver de nuevo sobre la frase de Jacques-Émile Blanche cuando decía que "Rodin no era un escultor, era un profeta"; observación que mostraba una interacción recíproca del arte y la vida. Pero, zacaso esta expresión constituye una muestra de reconocimiento, o también se halla detrás de un entusiasmo soberano por parte de sus contemporáneos? Por los años de esta declaración, sabido es que Rodin era diana de conclusiones decisivas que emanaban de su polémica obra El Balzac. Ahora bien, antes de proseguir, y sin abandonar el tema que nos ocupa, Los Burgueses de Calais, Rodin, a la hora de plantear esta obra, demostraba un entendimiento muy claro de aquello que pretendía poner de manifiesto, como era el principio de solidaridad humana ante una situación común, como son las pruebas de coraje dejando atrás la abominable villanía, aunque suscite paciencia y resignación.

Llegados a este punto, se procederá a examinar entre aquello que Rodin disponía ("Je vouláis faire sceller mes statues, les unes derrière les autres, devant l'Hôtel de Ville de Calais") y lo que las crónicas apuntaban (los acompañamientos coordinados de Los Señores de Calais, al escalonar en su seguimiento al "plus riche bourgeois de la ville qui s'appelle seigneur Eustache de Saint-Pierre"). En la realidad se prescindió del capitán de la villa, Jean de Vienne, quien al remate del asedio es informado por los barones del rey que deben entregar las llaves de este baluarte en el Canal de la Mancha y presentarse ante Eduardo III, quien señala "haré de ellos mi pura voluntad". En tal exigencia, como ya quedó indicado, parece anidar la idea de que el monarca tenía pensado un acto de castigo. De todas formas, tal criterio es conceptual, como se viene observando hasta el momento.

Como resumen del texto de Jean Le Bel ${ }^{31}$, la propuesta de Eustache de Saint-Pierre es planeada fríamente por los otros cinco ciudadanos "para salvar a su pueblo del exterminio". En todo caso, hay una observación a considerar, y que revela muy claramente Alfred Delvau sobre el planteamiento de ciertas tramas narrativas de relatos célebres del medievo en la segunda mitad del siglo XIX ${ }^{32}$. Conforme a las observaciones de Bernard Guidot en su amplia visión panorámica, para Alfred Delvau "era imposible conocer el espíritu medieval en su pureza original", por cuanto se exponía muy claramente a proceder a "un anacronismo consciente y probablemente calculado, al desarrollar puntos de vista muy modernos sobre las maneras en que se comportaban los caballeros gascones reproduciendo prejuicios del siglo XIX"33.

Como concepto central hay que decir que para Alfred Delvau, al igual que para A. Rodin, con el grupo de Calais se pone de manifiesto hasta que punto fue decisivo el control de la grandeza épica, junto con el conocimiento del gótico, que además, al igual que a los románticos, les permitió librarse del legado clásico. Por esta razón es comprensible la asignación de referencias al conjunto de Los Burgueses tan importantes de las esculturas góticas, como de las denominadas pinturas de trovador, que englobaban temas, sucesos e historias del medievo, así los amores funestos de Paolo Malatesta y Francesca de Rímini (Fig. 9), llevados al óleo por Ingres (1829), Coupin de la Couperie (1812)...

Desde los años 1880/1890 se favorece la libertad de expresión y un mayor desarrollo del tiempo libre; capítulo que contribuye a la manifestación de una cultura de masas, pero sobre todo al anticlericalismo republicano, al giro en la religiosidad, lo que supone una manera de sentir y de representar más laica, más escalonada hacia el mundo de los sentidos. Sin duda en el arte de realzar el desnudo, Rodin, quien sólo tiene por real los hechos demostrables, busca transmitir en Paolo y Francesca la expresión de los sentimientos personales, inmediatos al vigor 


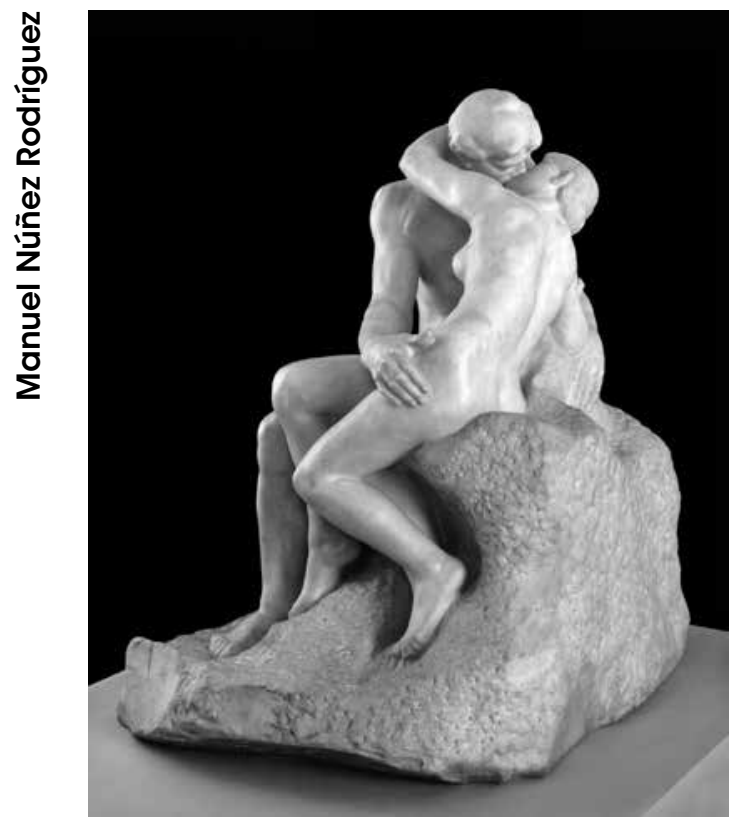

Fig. 9. Paolo y Francesca (El éxtasis, 1886-1898).

frenético. Pero, además, en la creación artística de esta llama erótica bajo el mármol, su campo de acción toma posesión de estudiados desnudos, como resultado de la observación directa con modelos profesionales. Denominado en algún momento como el escultor de la mujer y el amor, en este ejemplo cada uno de los personajes asume su iniciativa, como en los Amants Heureux de Fragonard (1770), Les Amants de Gericault (1815-1816), hasta concluir con la llamada carga emocional de El abrazo (L'Etreinte, 1903) de Pablo Picasso. Estas, y otras obras, establecen una aclaración muy neta sobre el planteamiento de las relaciones afectivas después que el Romanticismo hubiera tenido en cuenta un nuevo concepto sobre el arte y la vida, sobre la unión de la pareja; no en vano las muestras de afecto frecuentes centraban -la antaño denominada concupiscencia carnis- en los besos y caricias. La ternura sexual que muestran los amantes enlazados de Rodin, los dibujos del célebre Beso de Füssli (1816) o ciertos grabados de Munch (1895) sin duda son posturas posibles. Este tema, al igual que La Eterna Primavera, junto a otros, interpretados conforme a su temperamento, a su sensibilidad, no buscaban refugio en las transgresiones; por el contrario, eran estudios del desnudo, del lenguaje del cuerpo, para determinar los múltiples perfiles de los movimientos corpóreos y así capturar la vida como la naturaleza compone.

Una observación detallada de este grupo en bronce muestra a Francesca da Rimini y Paolo Malatesta como un conjunto macizo de marcado efecto volumen, cuyo fundamento sería un principio de realidad: el de la ubicación en un espacio verdadero, reivindicándolo como la verdadera sustancia de la escultura. Inspirado en un episodio de la Divina Comedia de Dante (Canto $V$, del Infierno), ambos personajes estaban leyendo las aventuras de Lanzarote y Ginebra (otra historia de un adulterio) en el momento de ser sorprendidos por Lanciotto Malatesta. Consciente Rodin de la arritmia de esta obra en el centro de la hoja izquierda de la llamada Puerta del Infierno, puesto que potencia el éxtasis amoroso de la pareja, no la condena, decide su autonomía y un mayor tamaño de la inicialmente conocida por la tradición popular como El Beso. La mayor expresión plástica, extensamente estudiada en su lenguaje corporal con efecto "carneviva", hace vibrar el mármol con sus ondulaciones emocionales, para expresar la interacción de las muestras de afecto, de manera que el comportamiento kinésico transmite una impresión de firmeza en las técnicas de relajamiento y dominio del cuerpo bajo las transparencias y los sombreados que evolucionan al ritmo de la llamada energía de movimiento, al tiempo que se ejercitan los sentidos. Una vez más cobra valor la propia norma y justificación de Rodin: "el arte no existe sin vida". De igual modo, se impone no anclar a Rodin en un viejo prejuicio con el que tomó las oportunas medidas: ajeno a libertinajes y torpezas, los temas galantes no se identificaban con su obra.

Sobre la exploración de los sentidos y el ejercicio de los sentimientos, resulta eficaz el mensaje emisor que se establece entre cada uno de los seis Burgueses de Calais. Como resumen hay que decir que la expresión facial es, según quedó analizado en el atlas del rostro de Pierre de Wissant, una coincidencia estructural con la grandeza trágica, el terror, la carga emotiva. Pero también es digno de tenerse en cuenta precisamente la paciencia y resignación de Eustache 
de Saint-Pierre; de igual manera, el gesto de desafío (¿a la muerte?) de Jean d'Aire, dispuesto a la siniestra del anterior. Ambos son los únicos que aportan pruebas de tener presente todo cuanto afecte al alma. En propuestas puntuales como Andrieus d'Andres, apretando el cráneo con sus manos para adoptar un gesto desgarrado, desgañitándose con la cabeza inclinada, el resultado es por el contrario de una extremada y patética exasperación. Escultura que, por otra parte, quedó asociada al burgués que en tales circunstancias es consciente de que, para "salvar este pueblo con mi muerte", resta analizada con un decisivo comportamiento kinésico o lenguaje de los movimientos corporales, centrando la elocuencia de los denominados gestos en el planctus ante nescia ${ }^{34}$. En otras palabras, puesto que se trata de aportar significados a una comunicación no verbal, se impone considerar con el movimiento de las articulaciones (brazos, manos, cuerpo inclinado, cabeza) el efecto lamento, expresar la sensación de impotencia ante lo que no se sabe que pueda ocurrir. Dimensión importante, pues, en estas circunstancias, los burgueses en camino hacia el campo de batalla inglés, todavía son desconocedores de la actitud intermediaria de la reina Philippa de Hainaud ante su esposo Eduardo III.

Dentro del amplio campo de expresiones, en Jean d'Aire, portador de las solicitadas llaves de la villa de Calais, se pone de manifiesto una planificación precisa de los ejes de piernas y brazos para un apercibimiento frontal con un rostro marcado por la deshonra de la capitulación, lo que constituye la esencia de una relación interpersonal con el público. Por ello, en su expresión facial, la mirada cumple, como tambien actúa el lenguaje corporal llegado el momento de entregarse como victimas expiatorias para salvar a los otros habitantes. En lo relativo a la ausencia de la ejecución real, quedaba abierta toda una serie de aporías que mantenían gestos externos de dolor et gemitus para observar el carácter de una situación difícil y con ello reforzar la interacción del receptor con tan enrarecida atmósfera o mise en scène. En la necesaria valoración hecha por Rainner María Rilke, podría decirse que "aquellos movimientos plásticos generados en las superficies del volumen, consecuencia de pronunciamientos o semicauces en contacto con la luz, acoplando reflejos y penumbras, salen al encuentro del espectador y vuelven a distanciarse" 35 .

En consecuencia, tal procedimiento escultórico en el centro de un espacio sin límites precisos, que podría definirse dinámico y tridimensional, contribuye a mantener la atención del público y a crear, como bien valora Rilke, "un campo de tensiones". Pero la imagen también enfatiza, despierta, en otros puntos a refrendar. Así, con el citado Jean de Fiennes (detrás de Pierre de Wissant, a la derecha de Eustache de Saint-Pierre), de quien Rodin experimentó variantes con el torso (1885), desnudo (1886), en su cabeza (1886-1887), pone de manifiesto la mejor época de la vida. Se trataba de plasmar, al igual que La Edad de Bronce, la primera etapa de la vida o despertar de la razón. Y aunque oculta, por disposiciones cronísticas, la importancia que posee el propio cuerpo, en el conjunto del grupo destaca el marcado interés por proporcionar las distintas edades del hombre.

Finalmente, hay otra cuestión a poner de manifiesto de manera, quizás, más perentoria, llegado el momento de proceder, de adentrarse, en la antesala del símbolo; en tanto que concepto esencial de toda acción humana. Así, al mismo tiempo que iba cobrando forma el grupo de Calais, realizaba en 1888 para el editor Paul Gallimard las correspondientes ilustraciones de Las flores del mal de Baudelaire. Se impone aquí preguntarse si cada uno de estos seis personajes, o alguno en concreto, podría estar en consonancia con esta fuente de información. En esto Rodin, a la vez que descubre el tiempo de la narración y el tiempo de la historia, proyectando aspectos culturales (lo que se denomina imagen valorativa) y que pueden representar un reforzamiento simbólico de los alcances que reflejan, el artista también inventa la realidad que manifiesta mediante la expresión de cuanto crea. Para ello hace uso de actitudes, gestos, silencios... que va construyendo. Ahora bien, no se impone como necesidad la presencia del monarca inglés Eduardo III en el momento de poner remate al asedio de Calais aquel 4 de agosto de 1347. Pero sí, como plantea Baudelaire en Las flores del mal, propone a humillación pública a quienes denomina "los lisiados de la vida". De manera que, el contacto visual del espectador con la obra es in- 
separable de la fuerza expresiva de "esas manos que hablan" y que tantas veces han quedado asociadas al taller de Rodin, como en especial a Camille Claudel, "las actitudes, los rostros con diferentes conductas y formas de mirar" ${ }^{\prime 36}$.

En definitiva, todas estas conductas, que comienzan con la desesperación y concluyen con el pesimismo y la resolución estoica, testimonian a seres abatidos en principio por el infortunio. Confiscación que desposee a tales "seres lisiados de la vida" de toda eficacia. Llegados a este punto, todo parecía indicar que esperaban ser ajusticiados. Ahora bien, según quedó resaltado varias veces a lo largo de este trabajo, Jean-
Marie Moeglin ya presentaba como reparación final un acto de contrición ajustado a la pena suplementaria de harmiscara. Asimismo restará siempre la ambigüedad para determinar si serían sacrificados por Francia o por Calais, aunque la III República también marcaba distancias con el ajusticiamiento. Resta por añadir un dato: el hallazgo hecho en la Torre de Londres de documentos que atestiguan el compromiso de Eustache de Saint-Pierre con Eduardo III de Inglaterra después de la caída de Calais. Dato que según J.-M. Moeglin ${ }^{37}$, de alguna manera introduce cierta ambigüedad en torno al mito de Los seis Burgueses.

\section{NOTAS}

${ }^{1}$ Maurice Agulhon, Marianne au pouvoir: I'Imagerie et la symbolique républicaine de 1880 à 1914, Flanmarion, Paris, 1989, pp. 50-52.

2 Por aquel entonces su amigo Étienne Dujardin-Beaumetz, pintor y ministro de bellas Artes, habrá de contribuir a la disposición de esta escultura, despojada de las Musas que rodeaban el cuerpo desnudo del escritor, en los Jardins du Palais-Royal el 30 de noviembre de 1909. Habrá que volver más adelante sobre este autor, puesto que a él corresponde la definición sobre el cometido del Estado en materia de arte, más para defensa del arte oficial que guiado por el interés de la instrucción pública.

3 H.C.Étienne Dujardin-Beaumetz, Entretiens avec Rodin (cfr. A.E. Elsen, Rodin, Phaidon, New York, 1963, p. 23).

${ }^{4}$ Hans Joachim Albrecht, Escultura en el siglo XX, Blume, Barcelona, 1981, pp. 120-121.

${ }^{5}$ Hans Joachim Albrecht, op. cit., pp. 159-162.

${ }^{6}$ Ionel Jianou, Rodin, prefacio de C. Goldscheider, Arted, Paris, 1970, p. 8.

${ }^{7}$ Hans Joachim Albrecht, op. cit., pp. 83-86.

${ }^{8}$ Hans Joachim Albrecht, op. cit., pp. 92-93, 126... Otro componente particular es el tratamiento del plinto o supresión por una base (cfr. pp. 128129).

${ }^{9}$ Ionel Jianou, op. cit., p. 12.

${ }^{10}$ Robert Sobieszek, "Sculpture as The Sum of its Profiles: François Willème and Photosculpture in France", The Art Bulletin, December 1980, pp. 617630, espec. 617-618.

11 Sobre este apartado cfr. Ionel Jianou, op. cit., pp. 7-9.

12 Con motivo de la muestra fue publicado el catálogo Du côte de chez Jacques-Émile Blanche, Paris, 2012, Fondation Pierre Bergé-Yves Saint Laurent/Skira Flammarion. En esta exposición se hacía referencia a los retratos de los contemporáneos de Rodin, así Marcel Proust, Edgar Degas, Maurice Barrès, Robert de Montesquiou, Jean Cocteau; este último fue un amigo próximo del propio escultor en sus años finales, como también André Gide, o el propio Igor Stravinski; precisamente de este compositor, creador del Concierto para violón o Edipus rex, también figura otro retrato al óleo.

13 Jean-Marie Moeglin, "Edouard III et les six bourgeois de Calais", Revue Historique, CCXCII/2, 1994, pp. 229-267 ; Charles Maingon, Émile Verhaeren. Critique d'Art, G. Nizet, Paris, 1984, pp. 154-161, espec. 154-156.

14 Joseph Polzer, "Rodin et Carpeaux", L'Information d'Histoire de
I'Art, n 4, 1971, pp. 214-224, espec. p. 216.

15 Jean-Marie Moeglin, Les bourgeois de Calais: essai sur un mythe historique, Albin Michel, Paris, 2002.

${ }^{16}$ Paul Gsell, Auguste Rodin. L'Art, entretiens réunis par Paul Gsell, Grasset, Paris, 1911, p. 68.

${ }^{17}$ Hans Joachim Albrecht, op. cit., pp. 92-93, 125.

${ }^{18}$ Paul Gsell, op. cit., capítulo VII, p. 191.

19 Jean-Marie Moeglin, op. cit., pp. 236-237.

${ }^{20}$ Hans Joachim Albrecht, op. cit., p. 125. Este autor analiza la práctica utilizada por Alberto Giacometti al elevar sus figuras sobre una plataforma, encontrando una correspondencia con las "figuras que caminan" de Rodin (pp. 125 y 126, nota 75).

${ }^{21}$ Jean-Marie Moeglin, op. cit., pp. 264-266.

22 Jean-Marie Moeglin, op. cit., p. 234.

${ }^{23}$ Paul Bert, De l'éducation civique, 1882. conf. Mona Ozouf, "Quand la République s'apprenait au tableau noir", Mille ans d'École, Les collectiones de l'Histoire, n 6, 1999, pp. 60-65, espec. p. 64.

${ }^{24} J$ ean-Michel Gaillard, "Les victoires de Jules Ferry", Les collectiones de I'Histoire, n 6, 1999, pp. 42-53, espec. p. 45. 
${ }^{25}$ Yvon Taillandier, Rodin, Ediciones Daimon, Madrid-Barcelona-Lugano, 1967, p. 91.

${ }^{26}$ Constantino Falcón, Emilio Fernández y Raquel López, Diccionario de Mitología Clásica, vol. I, Alianza Editorial, Madrid, 1999 (reimpresión), pp. 158-159.

${ }^{27}$ Paul Gsell, op. cit., p. 70.

${ }^{28}$ Joseph Polzer, op. cit., pp. 214224 , espec. p. 216 , nota 7 , donde aclara la procedencia de estas palabras: a partir de una entrevista del año 1917.

${ }^{29}$ Joseph Polzer, op. cit., pp. 214224. Este artículo pocas veces recogido, a pesar del tiempo transcurrido, resulta todavía fundamental para el estudio de Rodin, al introducir un análisis comparado con Miguel Ángel y Dante, como referentes complementarios de una experiencia de conjunto evaluada por dicho autor como "renacimiento épico". Asimismo no duda en evaluar el estilo miguelangelesco del Pensador, buscando un paralelismo en la tumba de Julián de Medicis. De igual manera adopta una actitud receptiva a la visión romántica del siglo XIX manifestada en muchos de los personajes de Rodin, invocando tanto a Miguel Ángel como a Dante y Virgilio en los Infiernos, o la muerte de Sardanápalo, ambas del pintor Delacroix, llegado el momento de referirse incluso a la actitud o gesto de la Danaide, aunque quede asociada al Art Nouveau. Joseph Polzer, op. cit., p. 216.

${ }^{30}$ Joseph Polzer, op. cit., p. 216.

31 Marie-Thérèse de Medeiros, "Dans le sillage de Jean Le Bel. La chute d'Edouard II chez Jean d'Outremeuse et chez Froissart", Cahiers de recherches médiévales et humanistes, n 10, 2003, pp. 131-142; Jean-Marie Moeglin, op. cit., p. 232.

32 Benard Guidot, "La manière d'Alfred Delvau. Un nouveau regard sur le Moyen Âge", La tradition épique, du Moyen Âge au XIXe siècle, Cahiers de recherches médiévales et humanistes, no 12, 2005, pp. 83-101, espec. p. 84.

${ }^{33}$ Bernard Guidot, op. cit., pp. 83 y 87.

${ }^{34}$ Barbara Pasquinelli, // gesto e I'espresione, Mondadori, Milano, 2005, "Gesti della disperazione", pp. 155191.

${ }^{35}$ Hans Joachim Albrecht, op. cit., pp. 86, 93-94, 126.

${ }^{36}$ Yvon Taillandier, op. cit., pp. 37 y 77 .

${ }^{37}$ Jean-Marie Moeglin, op. cit., p. 450-461 